Revista Iberoamericana, Vol. LXXXII, Núm. 254, Enero-Marzo 2016, 103-121

\title{
"SOY IGUAL QUE VOSOTRAS. SOLO ME APARTA UN SIGNO ARBITRARIO Y TERRIBLE...": FEMINISMO, NACIONALISMO Y MALINCHISMO EN LA JUDITH (1952) DE ROSARIO CASTELLANOS
}

\author{
POR \\ ROSARIO DE SWANSON \\ Marlboro College \\ Lo supe de repente: \\ hay otro. \\ $Y$ desde entonces duermo sólo a medias \\ y ya casi no como. \\ No es posible vivir \\ con este rostro \\ que es el mío verdadero \\ y que aún no conozco.
}

Rosario Castellanos, "Revelación"

Aunque en Latinoamérica el reconocimiento cabal de la contribución de la mujer en la construcción de la cultura nacional ha sido un proceso lento y esporádico, en México su contribución ha sido doblemente obstaculizada debido a que tanto en el periodo posterior a la independencia como en el periodo posrevolucionario el problema de la identidad nacional se presentó fundamentalmente como un problema masculino (Franco, Conspiradoras 169). Debido a ello, fueron principalmente los autores quienes a guisa de filósofos reyes se dieron a la doble tarea de discutir los problemas de la nación en obras literarias a la par de ocupar cargos políticos por medio de los cuales intervenían abiertamente en los procesos de formación nacional. ${ }^{1}$

\footnotetext{
1 El doble papel de los intelectuales en Latinoamérica es visible en casi toda la producción literaria y ensayística del siglo XIX y de principios del XX. Existe una abundante bibliografía al respecto; vea por ejemplo: Spanish American Literature Since Independence (1973) y The Decline and Fall of the Lettered City: Latin America in the Cold War (2002). Jean Franco, Transculturación narrativa en América Latina (1982) y La ciudad letrada (1984) de Ángel Rama, Identidad cultural de Iberoamérica en su narrativa (1986) de Fernando Aínsa, Colonialism and Culture:Hispanic Modernisms and the Social Imaginary (1992) de Iris Zavala, y Modernismo, Modernity, and the Development of Spanish American Literature (1998) de Cathy Jrade.
} 
La doble función del intelectual como político y como suerte de gestor cultural es discernible en las figuras de José Vasconcelos y de Alfonso Reyes, por ejemplo, pero alcanza máximo esplendor en la trayectoria de Octavio Paz y de Carlos Fuentes. ${ }^{2}$ No obstante su papel trascendental, la mayoría de los autores identificaba a la mujer con el territorio nacional o con el espacio de la pérdida. Las mujeres parecían ocupar un espacio entre signos: ya como catalizadoras de la identidad o bien como problema de índole nacional, como sucedió con la Malinche, pero nunca como sujetos productores de la misma. ${ }^{3}$ En cierto modo, la recepción de la participación de la Malinche en la Conquista ilustra que la interpretación de hechos históricos no acontece separada de discursos en torno al lugar que la mujer y los pueblos conquistados ocupan dentro del imaginario nacional sino que es parte intrínseca del proceso de formación nacional.

Con todo, en el periodo posrevolucionario la incursión de un mayor número de mujeres en el campo de las letras produjo un cambio. Las escritoras por escribir desde su experiencia como mujeres se dieron cuenta de que al escribir debían enfrentarse con todo un repertorio de mitos propios y heredados de la tradición greco-romana y bíblica en los que las mujeres no llegaban a significar, o únicamente alcanzaban significación a través de la abnegación, del auto sacrificio; y además, en caso de negarse a hacerlo eran consideradas traidoras. ${ }^{4}$ Esto no significa que anteriormente no haya habido escritoras que trabaran diálogo con los mitos sobre la mujer (Sor Juana es notable entre ellas) sino que este grupo tiene en su haber las herramientas del feminismo como movimiento pujante que alcanza madurez junto con ellas como demuestra la vida y la obra de Rosario Castellanos. En efecto, el corpus de Castellanos arrastra en su cauce la fuerte impronta dejada por Simone de Beauvoir, Virginia Woolf y Simone Weil (Ahern xiv). ${ }^{5}$

Castellanos al ir en pos de su voz como escritora se vio forzada a confrontar su reflejo en el espejo nacional, a examinar críticamente el repertorio de mitos propios y

2 Vea Literatura hispanoamericana e ideología liberal (1976) de Hernán Vidal y A companion to Latin American Philosophy (2010) editado por Susana Nuccetelli, y otros.

3 La Malinche no es el único actor histórico que se suma al contingente español aunque se la culpe de la caída de todo un imperio. Existen varios textos que intentan rescatar su figura como sujeto histórico además de rastrear la construcción de su mito en diferentes periodos: Women in Hispanic Literature (1983) editado por Beth Miller, La Malinche in Mexican Literature (1991) de Sandra Messinger Cypess, Between Worlds: Interpreters, Guides and Survivors (1994) de Frances Karttunen, La Malinche, sus padres y sus hijos (1994) editado por Margo Glantz, "Refocusing New Spain and Spanish Colonization: Malinche, Guadalupe, and Sor Juana" (2005) de Electa Arenal y Yolanda Martínez-San Miguel y finalmente Malinche's Choices (2006) de Camila Townsend. Para una discusión más amplia del contexto político general en Mesoamérica en la víspera de la Conquista vea Mexico and the Spanish Conquest (2006) de Ross Hassig.

4 Vea Las conspiradoras (1994) de Jean Franco.

5 Castellanos muere en 1974, justo un año antes de que se celebre en México la Primera Conferencia Internacional sobre la Mujer en la que se discuten muchos de los problemas que Castellanos confronta en su vida personal y discute en su obra.

Revista Iberoamericana, Vol. LXXXII, Núm. 254, Enero-Marzo 2016, $103-121$ ISSN 0034-9631 (Impreso)

ISSN 2154-4794 (Electrónico) 
heredados -Dido, Hécuba, a Malinche, la Virgen de Guadalupe, la madre, la soltera, la lesbiana, la mujer indígena- entre otros. ${ }^{6} \mathrm{Su}$ confrontación con el espejo nacional la lleva a comprender que la relación entre la mujer como sujeto histórico y "la mujer" producida por los discursos hegemónicos, expresada en el lenguaje y en sus formas discursivas, tiene consecuencias nefastas para la mujer en el ámbito socio cultural (Lauretis 1-8). De ahí que, como nos recuerda Maureen Ahern, al tratar de encontrar su propia voz Castellanos descubriera el silencio de otros (xiii).

Es a través de su lectura penetrante de mitos que Castellanos aprende que en tanto que aprendemos a leer textos, lo que en realidad aprendemos no son textos sino paradigmas de comportamiento y que los métodos por los cuales se les asigna valor estético o universal a éstos no son infalibles sino que están llenos de prejuicios que a su vez informan nuestras respuestas estéticas y nuestras prácticas sociales (Kolodny 176). Castellanos cae en la cuenta que, para la mujer, la profesión de letras requiere de una lectura rigorosa e incisiva de los mitos heredados y propios para ver cómo funcionan antes de darse a la tarea de reescribirlos para encontrarles salida. En otras palabras, Castellanos se da cuenta de que la escritura es una práctica con consecuencias sociales y que para la mujer toda lectura debe convertirse en una estrategia de escritura como arma de resistencia cultural, de ahí su lectura penetrante de mitos, de ahí su feminismo, de ahí su comprensión del otro. Es justamente por ello que la adaptación que Castellanos hace de la historia de Judith, la célebre heroína de la resistencia cultural del Viejo Testamento, es una heroína sin brillo, una heroína más bien sombría y hasta apocalíptica.

El objetivo central del presente ensayo es examinar "Judith" (1952) el poema dramático de Rosario Castellanos basado en la célebre heroína del Viejo Testamento. Antes de entrar de lleno en el análisis de la versión de Castellanos, se hace un recuento de la recepción de "El libro de Judith" paso necesario para comprender los problemas que Castellanos identifica con dichas lecturas y que luego echa por tierra en su adaptación. Por último, se discuten los nexos entre las figuras de la Malinche y la figura de Judith que Castellanos descubre, fuente al fin del carácter siniestro de su obra. Conviene mencionar que "Judith" se usa para referirse a la obra de Castellanos, en tanto que "El libro de Judith" se refiere al texto del Antiguo Testamento mientras que Judith a la figura literaria en ambos textos. El giro siniestro que Rosario Castellanos inserta en su interpretación de Judith, está dirigido a la desconstrucción de las falacias y peligros de su mito y a la creación de un espacio para un modelo de mujer heroína diferente.

\footnotetext{
6 Vea los siguientes textos clave: A Rosario Castellanos Reader (1988) de Maureen Ahern y Meditación en el umbral: Antología poética (1985) de Julián Palley. Más recientemente, "Rosario Castellanos at the Edge of Entanglement" (2008) de Estelle Tarica, "Feminist Insurrections" (2007) de Adriana J. Bergero y Elizabeth A. Marchant, "Utopía y distopía en Salomé, una pieza teatral poco conocida de Rosario Castellanos" (2012) de Rosario de Swanson y "Breaking the Bonds of Domination" (2013) de Zoe Brigley Thompson han iluminado puntos oscuros en la obra de Rosario Castellanos.
}

Revista Iberoamericana, Vol. LXXXII, Núm. 254, Enero-Marzo 2016, $103-121$ ISSN 0034-9631 (Impreso) ISSN 2154-4794 (Electrónico) 


\section{JUDITH EN LA TRADICIÓN JUDEOCRISTIANA}

"El libro de Judith", en el cual Castellanos basa su drama, fue escrito hacia 135-78 A de C. en Alejandría o Palestina por un autor anónimo. Se considera como un ejemplo temprano de novela y como uno de los primeros ejemplos de literatura didáctica que hace referencia a la fe y a la conversión como aspectos importantes del ser judío en la era helénica. Además es clave en la historia de la escritura porque marca la transición de pergamino a la invención del libro en el formato como se conoce hoy día. Aunque inicialmente "El libro de Judith" no formó parte de la Biblia hebrea sino hasta después del siglo X, cuando fue incorporado en midrash (historias judías) y en piyyut (oraciones), su inclusión en la llamada Biblia Septuaginta o Biblia de los Setenta, una de las primeras traducciones de las escrituras hebreas al griego usada por los primeros cristianos, influyó la recepción cristiana del mismo. De tal suerte que en la tradición cristiana Judith se considera un modelo de piedad que anuncia a la Virgen María, mientras que en la tradición hebrea, Judith es considerada como la heroína de la resistencia cultural (Brine 6-13).

"El libro de Judith" tiene lugar durante el periodo del Segundo Templo cuando la comunidad de Israel acababa de restablecer su templo en Jerusalén después de un periodo de cautiverio a manos de Babilonia. El texto narra la historia de Judith, una viuda que vive en la ciudad de Betulia cuando está a punto de caer en manos de Holofernes, el general asirio enviado por Nabucodonosor para conquistarla. Holofernes envía a Ajior como emisario antes de tomarla por la fuerza pero Betulia resiste dado que Jerusalén depende de ella. Sin embargo, al cabo de treinta y cuatro días de sitio, sus fuentes de agua están agotadas y sus habitantes han caído presa del miedo y del desaliento. Al ver el sufrimiento de su pueblo, su jefe Ozías convoca una asamblea y promete que si Dios no se apiada de ellos en cinco días entregará la ciudad a los asirios para que todo vuelva a la calma. Al escuchar esto, Judith, la viuda de Manasés, reprocha a los dirigentes su falta de fe y promete liberar a su pueblo. Judith se encomienda a Dios, se quita el saco de viuda, viste con sus mejores galas y acompañada por su sirvienta se dirige con bolsas llenas de vino y de viandas al campamento enemigo. Una vez ahí, Judith seduce a Holofernes, el general del ejército asirio. Llegada la noche, éste con intención de violarla, envía a su sirviente el eunuco Bagoas a que la invite a celebrar en su tienda. Judith brinda con él hasta que Holofernes cae presa de una embriaguez profunda. Acto seguido, Judith le corta la cabeza, la coloca en la bolsa de las viandas y junto con su sirvienta emprende el regreso triunfal a Betulia. En Betulia, Judith es declarada "la gloria de Jerusalén, el orgullo supremo de Israel". Al día siguiente los asirios descubren el cadáver decapitado de Holofernes y aterrorizados de Dios se lanzan a la fuga. Entretanto, Judith libera a su sirvienta y, aunque se convierte en una mujer muy famosa y cortejada por muchos, regresa a su antigua vida de viuda ascética. Judith muere a la edad de ciento cinco años y es sepultada junto con su esposo Manasés (Biblia latinoamericana, Judith 1-16).

Revista Iberoamericana, Vol. LXXXII, Núm. 254, Enero-Marzo 2016, $103-121$ ISSN 0034-9631 (Impreso) 
Según Kevin R. Brine, si bien la historia de Judith es famosa porque su heroína seduce y decapita a Holofernes, el éxito de Judith se debe a que ella personifica el mito del judaísmo mismo: la supervivencia cultural contra todo pronóstico a través de la fe en Dios (3). Para Margarita Stocker Judith es una de las protagonistas más memorables en la literatura hebrea porque con su valor y heroísmo salva a su pueblo. Judith es la personificación misma de la nación dado que su nombre significa judía, de ahí el nacionalismo triunfal de la historia (5). Por su parte, Amy-Jill Levine explica que Judith encarna simbólicamente a la nación y por ello "El libro de Judith" puede ser considerado como uno de los primeros textos que trata el tema de la alegoría nacional (17). No obstante, Levine advierte que si bien resulta tentador ver a Judith como una heroína que pone en tela de juicio la construcción normativa de los héroes de la nación como hombres, es importante recordar que es precisamente su carácter fuerte y excepcional lo que requiere su domesticación al final del texto (16-19). Por esta razón, a pesar de ser la salvadora de su nación, al final del texto Judith regresa a la vida sencilla de las otras mujeres de las cuales una vez se distinguió. Además, conforme con el patrón de las novelas de alegoría nacional, en las que la nación es representada por una mujer, aunque Judith sigue siendo identificada con la nación de Israel, al final vuelve a la anonimidad y domesticidad del espacio femenino que como mujer le corresponde (Levine 20).

Además, Stocker señala que el "El libro de Judith" hecha mano de una serie de oposiciones (israelitas-asirios, monoteísmo-paganismo, Nabucodonosor/idólatra-Dios, Judith-Holofernes) para destacar el poder absoluto de Dios. Por esta razón, el elemento más importante de "El libro de Judith" no es que una mujer sea su heroína sino más bien su reconocimiento y exaltación del poder como concepto fálico puesto que en última instancia el único poseedor de la masculinidad suprema y el poder que viene con ella es Dios. Judith es más que el mero instrumento de su poder. Judith es la esclava del señor, por tanto, aunque incite el deseo, como símbolo de la comunidad judía Judith está casada con Dios y por ello permanece casta (Stocker 4-8).

En cambio en la perspectiva cristiana, el comportamiento ejemplar de Judith al encarar grandes dificultades, su inquebrantable fe en Dios, su papel como mediadora de su poder, su castidad y retorno final a una vida sencilla y anónima hacen de Judith un modelo de piedad que más tarde sería encarnado en la Virgen María. Además, dado que la castidad, siendo ella viuda, es lo más cercano a la virginidad y dado que al decapitar a Holofernes decapita el pecado de la lujuria, Judith cancela por completo las acciones de Eva y de Dalila, dos de las femmes fatales más notables del Viejo Testamento. Por esta razón, tanto el padre Jerónimo, traductor de la biblia al latín, como el obispo Clemente, tercer obispo de Roma, interpretan a Judith como precursora de la Virgen María y como puente entre el Viejo y el Nuevo Testamento (Stocker 4).

Pero además, Stocker señala que aún usando una perspectiva no religiosa y más contemporánea como el psicoanálisis la figura de Judith está estrechamente ligada a la

Revista Iberoamericana, Vol. LXXXII, Núm. 254, Enero-Marzo 2016, $103-121$ ISSN 0034-9631 (Impreso)

ISSN 2154-4794 (Electrónico) 
perspectiva patriarcal dado que la muerte por decapitación se asocia con la castración. Si bien el hecho de que sea una mujer quien decapita a Holofernes presupone la envidia del pene como móvil principal, el hecho de que Judith coloque la cabeza de Holofernes en la bolsa de comida le da un toque monstruoso a su figura: la convierte en una especie de vagina dentata usada por Dios para disuadir a quienes se atrevan a desafiar su poder. En este sentido, Judith encarna los temores masculinos acerca de la femineidad. Por esta razón, la femineidad que triunfa por encima de la masculinidad no está diseñada para ser feminista porque la femineidad de Judith está dirigida a acentuar la virilidad de Dios (9-11). Por consiguiente, "El libro de Judith" sigue de cerca los patrones de conducta prescritos para la mujer dentro del patriarcado: la mujer es importante en tanto que es instrumento necesario para la realización del poder masculino representado por Dios. De ahí que su fama y su figura sean incorporadas como modelos paradigmáticos de comportamiento femenino pasado de generación en generación dentro de un guión cultural producido y controlado por el patriarcado de bases judeocristianas, discurso heredado en México por vías religiosas. Por lo tanto, el toque siniestro y apocalíptico de la adaptación que Castellanos hace de "El libro de Judith" se debe a que su heroína se rehúsa a cumplir con el papel prescrito para ella en el guión cultural del patriarcado, ilustrado en el mito de Judith.

"Soy igual que vosotras. Solo me aparta un signo arbitrario y terRible..."

La "Judith" de Castellanos tiene lugar en Chiapas en un pueblo de la Tierra Caliente sitiado por el ejército enemigo en la época revolucionaria. Mas a diferencia del texto bíblico, en la "Judith" de Castellanos existen solamente tres personajes principales, Judith, Juan y Gabriel, además de un grupo de mujeres del pueblo cuya función es similar a la de un coro griego. Otra diferencia importante es el hecho de que aunque en cierto momento a Judith le nace el deseo de defender a su pueblo, este es un sentimiento pasajero y al final debe ser obligada por el poder a que cumpla su papel de heroína conforme a las normas del patriarcado.

La acción del drama se desarrolla en el interior de una alcoba nupcial humilde con piso de tierra. Es la noche de bodas de Juan y de Judith pero sus nupcias dado el contexto histórico, no producen júbilo sino presagios funestos. Nueve mujeres vestidas de negro dictan una por una su sentencia hasta pronunciar la condena final antes de salir: "Porque a escondidas ríen / mientras su pueblo sube a la horca y la noche / viene como cuchillo entre los dientes" (Castellanos, "Judith" 344). Entran los novios vestidos de blanco. Intercambian promesas de amor antes de la entrega. Judith jura sumisión: "Mírame. Vengo limpia hasta de mi memoria. / No tengo altar ni tribu. / Desde hoy eres mi dios, mi casa y mi camino"(345). Juan la acepta: "Llevo tu voluntad entre las manos / como el brío de una yegua" (345). A través de este breve intercambio además

Revista Iberoamericana, Vol. LXXXII, Núm. 254, Enero-Marzo 2016, $103-121$ ISSN 0034-9631 (Impreso)

ISSN 2154-4794 (Electrónico) 
de la actitud sumisa de la mujer se subraya que su entrega al hombre en el lecho nupcial es total: no solamente la posee físicamente sino que también es dueño de su voluntad.

La escena amorosa es interrumpida por estampidos lejanos que atemorizan a Judith. Juan la conforta con susurros dulces interrumpidos por el sonido de disparos más cercanos y frecuentes. Judith parece comprender el peligro en el que se encuentra su pueblo; y por eso el momento de entrega y abandono cesa de tener importancia. Judith cuestiona el valor de Juan: “¿por qué estás aquí? ¿Por qué buscas mi cuerpo?/¿Por qué alargas tus manos a desgajar mis pechos / cuando en cada rincón hay un arma desnuda, / y es mejor que una esposa, aguardando a su dueño?" (347). Es interesante notar el uso de la comparación entre "el arma desnuda" y el cuerpo, desnudo también, de la mujer como esposa en actitud de entrega. Juan le reprocha el "nombre de cobarde" porque como "[sus] hermanos [ha] luchado" y "vendido [sus] días al peligro" (347). La carga sexual del encuentro se disipa en una discusión sobre el arrojo y la valentía como aspectos importantes de la masculinidad: “¿Pero no te enardeces bajo tantas espuelas? [...]/ Gritan: 'Judith, Judith', esos clarines [...]/ ¡Me están llamando, Juan, me están llamando!" (347). De este modo, más consciente del peligro de su pueblo y más valiente, Judith toma el machete pero Juan amenazador se interpone para que no salga; entonces Judith lo levanta y dice: “¡Entre mí y mi destino el muro derribado!” (349) pero antes de que pueda descargar el golpe, Juan se lleva las manos al cuello y cae fulminado.

Hasta este momento Judith parece atender el llamado a defender a su pueblo pero la muerte de Juan parece cancelar su efecto. Cuando las mujeres regresan aunque la compadecen aluden a su posible culpabilidad pero Judith se defiende: "Pero mi mano está / limpia. No ha recogido su cosecha. / Soy inocente. Juro / que Judith no es el nombre de esta muerte" (350). Aquí conforme al guión original, el marido de Judith muere por causa divina para que ella quede libre de llevar a cabo su cometido. La diferencia entre ambos textos radica en el hecho de que en Castellanos la entrega sexual no llega a consumarse y por eso Judith es una viuda "blanca"; su primera y única entrega será a Dios. En cambio en el texto bíblico, Judith ya ha consumado sus nupcias con Manasés que muere, presuntamente, a manos de Dios como resultado de una insolación, permitiendo de este modo que Judith reclame su castidad como mujer viuda que elige entregarse únicamente a Dios.

Las mujeres hablan entre sí hasta que una de ellas en papel de augur dice, "Esta muerte, Judith, es como un signo / dibujado en tu frente" (Castellanos, "Judith" 351). Entran más mujeres lamentando las desgracias ocurridas, quieren huir pero son increpadas por Gabriel, el enviado de los ancianos del pueblo que llega para ordenar a Judith a que acabe con el enemigo. Gabriel viste botas y porta la fusta del poder en sus manos con la que se subraya su alianza con el poder; pero un poder despótico encarnado en las botas y en la fusta, el atuendo típico del patrón. Su figura contrasta con la de Judith que viste ropa de percal y va descalza. Después de varias respuestas a modo de lamentaciones,

Revista Iberoamericana, Vol. LXXXII, Núm. 254, Enero-Marzo 2016, $103-121$ ISSN 0034-9631 (Impreso)

ISSN 2154-4794 (Electrónico) 
una mujer, haciendo eco de Judith, pregunta: “¿Y tú por qué has venido a hablar aquí? / ¿No estarías mejor afilando un cuchillo?” (355). Gabriel responde: "Por esta única vez el exterminio / no es tarea de hombres" (355) y "Una mujer es digna portadora de engaños [...]/ Los ancianos han dicho el nombre de Judith" (356).

María A. Salgado señala que el comportamiento "marcialmente viril" de Gabriel contrasta con la tarea de seducción encomendada a Judith (192). Con ello se subraya que en el patriarcado, a pesar del discurso de castidad, se explota la sexualidad femenina para "conquistar" y exterminar al enemigo. A través de esta yuxtaposición, se vuelve visible la división de esferas imperante dentro del sistema según la cual hacer la guerra es trabajo de hombres; en cambio, la seducción y hacer el amor trabajo de mujeres. Por consiguiente, Judith es una suerte de femme fatale al servicio del sistema dado que el patriarcado requiere el "patriotismo sexual" de la mujer siempre y cuando ésta, una vez cumplida su misión, no aspire a compartir el poder y acceda a ser retornada al ámbito doméstico que le corresponde y cuyos valores supone defender.

Por otro lado, la caracterización de la mujer como "portadora de engaños" hace alusión a la construcción de la Malinche en el imaginario nacional y sugiere que el engaño es innato en la mujer y por ello debe ser "domesticada", devuelta al espacio que le corresponde y controlada por "hombres de razón”. Por esta razón la indumentaria de Gabriel, la fusta y las botas, lo colocan en la posición del patrón, en la posición del estado patriarcal, la autoridad máxima a quien Judith como mujer debe someterse. No obstante, siguiendo el patrón de alegorías nacionales en las que la nación es representada por una mujer, la integridad física de Judith permanece impoluta. Ella es virgen a pesar de haber contraído nupcias con Juan porque ha sido elegida para llevar a cabo los designios del patriarcado, articulados por Gabriel como portavoz del sistema.

En cierto sentido, la figura de Judith evoca la de la soldadera, la mujer mexicana de raíces indígenas que también llegó a representar los valores más nobles de la nación mexicana y como Judith demostró ser dueña de una entereza y fuerza mayor al encarar grandes peligros. Al igual que Judith, las soldaderas aunque consagradas en la mitología nacional, no se beneficiaron de su participación en la resistencia campesina, como demuestra el personaje de Jesusa Palancares en Hasta no verte Jesús mío (1969) de Elena Poniatowska. Mitificadas en el corrido y en la literatura, su participación no les hizo acreedoras a ningún beneficio y fueron forzadas a reintegrarse al espacio doméstico de la nueva nación posrevolucionaria como empleadas domésticas, como sirvientas de un patrón, ocupando el último escalón social dentro de un sistema que se había beneficiado de su enorme sacrificio.

Por esta razón, Castellanos se aparta del texto bíblico creando una heroína que renuncia a la fama y se resiste a poner su sexualidad al servicio de un sistema que sabe se vendrá abajo sin su participación. En un intento por romper el binomio castidad-femme fatale en el cual la mujer parece estar atrapada, Castellanos se aparta del texto bíblico y

Revista Iberoamericana, Vol. LXXXII, Núm. 254, Enero-Marzo 2016, $103-121$ ISSN 0034-9631 (Impreso)

ISSN 2154-4794 (Electrónico) 
reescribe por completo su final. ${ }^{7}$ La desconstrucción del binomio castidad-femme fatale es doblemente necesaria porque el ideal de castidad y docilidad femenina encarnado por Judith, como avatar temprano de la Virgen María y de la Virgen de Guadalupe en México, coexiste además con su extremo opuesto: el modelo pernicioso de la femme fatale encarnado en la figura de la Malinche. Mas por otra parte, aun cuando dentro del patriarcado se requiera de "el patriotismo sexual" de la mujer en aras de su cultura, la división sexual de la labor justifica que la mujer no pueda acceder al poder de la polis. De ahí que la Judith de Castellanos sea una figura apocalíptica precisamente porque no cumple con el rol esperado, no pone su sexualidad al servicio del sistema para "proteger" su nación y con ello vuelve visibles las estructuras que atrapan a la mujer en un doble binomio: mujer casta-femme fatale o heroína-traidora. Como se ilustra en "El libro de Judith", "el patriotismo sexual" de la mujer en aras de su cultura es necesario dentro del patriarcado, la división de esferas dicta, empero que ésta sea devuelta al espacio doméstico que le pertenece y que supone defender. De ahí que Castellanos eche por tierra su mito.

\section{MALINCHISMO Y NACIONALISMO}

Según Federico Engels la división de esferas coincide con el desarrollo simultáneo del capitalismo y del patriarcado. En una antigüedad más bien remota, la acumulación de bienes dictó por cuestiones prácticas la división del trabajo, antes comunal, entre el propio para la mujer y el propio para el hombre dando como resultado la división de esferas. Sin embargo, una vez que dicha división se institucionalizó, el poder detentado en la esfera del hogar perdió valor en contraste con el poder inmanente en la esfera pública, inextricablemente ligada a la acumulación de bienes y a la expansión de capital, ocupada casi exclusivamente por hombres. Las consecuencias más profundas de esta evolución fueron la devaluación del trabajo propio de la mujer y su exclusión de la esfera del poder (Engels 66). La división de esferas propició y legitimó la definición casi exclusiva de la mujer en función de su biología como eje de reproducción (real y simbólica) de la comunidad. Esta definición a la larga se convirtió en uno de los principales mecanismos de control de la sexualidad de la mujer en la sociedad patriarcal.

Al mismo tiempo, dada su función reproductiva, a pesar de la pérdida de poder de la mujer en términos reales, su estatus como metáfora representativa de los valores más sublimes de la polis, supuestamente guardados en el seno del hogar alcanzó auge extraordinario. Según Claude Levi-Strauss la esencia de las reglas de parentesco que gobiernan el orden social se basa en el intercambio de mujeres generado a partir de la

7 En realidad este es un tema antiguo abordado por Sor Juana en su "Sátira filosófica" dirigida a los “Hombres necios...". Vea La respuesta (1994) editada por Electa Arenal y Amanda Powell (156-159).

Revista Iberoamericana, Vol. LXXXII, Núm. 254, Enero-Marzo 2016, 103-121 ISSN 0034-9631 (Impreso)

ISSN 2154-4794 (Electrónico) 
prohibición del incesto siendo ellas los bienes más valiosos precisamente por ser la base sobre la cual se fundamentan las relaciones entre sociedades (24-30). No obstante, a pesar de ser los bienes más valiosos, en este sistema de intercambios son los hombres como agentes de intercambio y no los "bienes" intercambiados quienes resultan serbeneficiarios de esta transacción. Esto significa que las mujeres como "bienes" intercambiados no están en posición de obtener beneficios de su propia circulación como "bienes". De tal modo que, en tanto que sean los hombres quienes actúen como agentes de intercambio, serán ellos los beneficiados y no las mujeres. Y más, la mujer como bien social opera como conducto de realización del poder detentado por los hombres como agentes de dicho intercambio y aunque ella es la pieza esencial no recibe ningún beneficio. De hecho sin su participación la estructura social se vendría abajo. ${ }^{8}$ Éste es el esquema que se nos presenta en "El libro de Judith": Judith como esclava del Señor es mediadora de su poder y por ello, una vez cumplido su cometido, debe regresar al espacio doméstico que como mujer le corresponde. Estas son las raíces del estado patriarcal que limita el acceso de la mujer al poder de la polis.

Por esta razón, las heroínas de la antigüedad no podían seguir fielmente el patrón del héroe masculino que arrostraba todos los obstáculos y, si sobrevivía, estaba destinado a ocupar la silla del poder sino que, debido a su función como eje de reproducción de la sociedad, las heroínas eran mujeres excepcionales, llamadas a cumplir un deber patriótico para una vez cumplida su misión ser devueltas al espacio doméstico, lugar que les correspondía. Esto no quiere decir que el encarnarse en la mujer los valores más sagrados de la nación np sea uno de los elogios más altos que se pueden recibir, lo es. El problema con este elogio es su función meramente representativa. Las mujeres son emblemas de la nación pero no detentan poder dentro de ella. La mujer se debe a su familia y no a la política. ${ }^{9}$ Este hecho parece colocar a la mujer en una encrucijada doble ya que, si se rehúsa a cumplir este papel, será vista como responsable del derrumbe total de un sistema que aunque se cimienta enteramente en ella y al que ella supone representar, la oprime confinándola casi exclusivamente al espacio doméstico.

En cierto modo ésta es la encrucijada que enfrentan las figuras paradigmáticas de Antígona ${ }^{10}$ y de la Malinche. Judith Butler, citando a Hegel, explica que la figura de Antígona marca la transición de la organización de la sociedad al sistema patriarcal y un cambio en las reglas del parentesco. Como figura de transición y oposición, Antígona

\footnotetext{
Vea la crítica a Lévi-Strauss en This Sex which is not One (1977) de Luce Irigaray 170-191.

9 Para una discusión más amplia sobre el papel y la condición de la mujer mexicana e indígena en el periodo posrevolucionario vea, "Utopía y distopía en Salomé, una pieza teatral poco conocida de Rosario Castellanos" de Rosario de Swanson 438-441.

${ }^{10}$ Existen varias adaptaciones del clásico drama de Sófocles, entre las más importantes destacan La pasión según Antígona Pérez (1968) de Luis Rafael Sánchez, Antigona furiosa (1986) de la argentina Griselda Gámbaro y Antígona (1991) de la escritora guineo ecuatoriana Trinidad Morgades Besari.
}

Revista Iberoamericana, Vol. LXXXII, Núm. 254, Enero-Marzo 2016, $103-121$ 
significa antigeneración y por eso está simultáneamente dentro y fuera del sistema de representación. Es decir, Antígona no puede hacer su reclamo fuera del discurso del mismo Estado que le niega representación; de ahí que su desafío al poder de Creonte, representativo del nuevo Estado patriarcal, termine en su muerte. Antígona, al sepultar a su hermano Polinices, cumple con su deber a la familia que como mujer le corresponde, mas dado que lo hace en el momento en que el poder ha sido arrancado del espacio doméstico, es castigada con la muerte. Por esta razón, Antígona no puede hacer su reclamo fuera del discurso del poder del mismo Estado que le niega representación. Como consecuencia, sus palabras no son las de un ente cuya agencia política puede sobrevivir y por ello, aunque su desafío es patente y es escuchado, el precio que paga por hablar es la muerte. Antígona aunque es una figura de resistencia, su figura todavía se identifica con el espacio de la pérdida (Butler 10-28). No obstante su muerte no es en vano puesto que su desafío vuelve visibles las estructuras de poder que opone.

En cierto sentido, la figura de la Malinche guarda cierto paralelo con la de Antígona, dado que también emerge en un momento de cambio crucial en México, cuando se cambia de un Estado indígena a un Estado español, ambos patriarcales. Sin embargo, a diferencia de Antígona, la Malinche no pertenece a la clase en poder y por esta razón, aun dentro del Estado indígena, es doble o triplemente negada: es mujer, no es azteca y es esclava. Además, su alteridad apenas cambia en el nuevo Estado español al que entra como mujer esclava no azteca susceptible de ser explotada sexualmente. Por esta razón, en contraste con Antígona que pertenece a la clase en poder, la Malinche no le debe lealtad a la nación azteca pues no pertenece a la élite. Por lo menos no en la forma en que una Doña Isabel Techichopotzin, la hija de Moctezuma quien también concibe un hijo de Cortés y termina casándose con un español, pudo haberla tenido. Quizá por esta razón, la Malinche no se opone enteramente al nuevo poder español, no resiste la ruina del sistema indígena sino que parece aliarse al poder español, y aunque no es la única (recuérdese a Doña Isabel Techichopotzin y a las naciones indígenas que luchan del lado español) se la culpa de la destrucción de toda una cultura. Conviene subrayar que la Conquista no fue un conflicto exclusivamente entre españoles y aztecas sino un conflicto cuyo eje central era la competencia entre distintos grupos indígenas (cempoalas y tlaxcaltecas entre otros) por el control político de Mesoamérica. Por ello, diferentes actores políticos aprovecharon la llegada de los españoles como oportunidad para apoderarse del control azteca y por eso se alían, inicialmente, con el bando español (Hassig 176-80). ${ }^{11}$ Sin embargo, dentro de la perspectiva nacionalista del Estado

${ }_{11}$ Para una descripción de las formas en que grupos indígenas ayudaron al contingente español vea "La carta del Consejo de Huexotzinco al Rey Felipe II, 30 de Julio de 1560" en Visión de los vencidos (1998) de Miguel León Portilla 169-174 y el mismo documento en la edición trilingüe (Náhuatl, Spanish, English) We People Here: Nahuatl Accounts of the Conquest of Mexico (1993) de James Lockhart 288297.

Revista Iberoamericana, Vol. LXXXII, Núm. 254, Enero-Marzo 2016, 103-121 ISSN 0034-9631 (Impreso)

ISSN 2154-4794 (Electrónico) 
posrevolucionario, dado que la Malinche no cumple con el papel prescrito para la mujer en la sociedad patriarcal, pues no parece defender los valores de su "patria indígena", se la culpa de la destrucción de toda una cultura. Como consecuencia, a diferencia de Antígona, su nombre o mito no se asocian con la resistencia, sino que han llegado a significar traición, "malinchismo".

En lo tocante al periodo de la Conquista, Susan Migden Socolow explica que era común entre las naciones indígenas otorgar a mujeres en calidad de regalos o en alianzas matrimoniales como estrategia para garantizar el poder indígena, práctica que continúa dentro del nuevo Estado español. En el caso de Doña Isabel Techichopotzin, a la muerte de Cuauhtémoc, su esposo y último emperador azteca, Doña Isabel es bautizada y más tarde concibe un hijo de Cortés. Al igual que la Malinche, Doña Isabel Techichopotzin contrae matrimonio con un español, recibe la lucrativa encomienda de Tacuba y vive el resto de sus días como encomendera rica pero pasa a convertirse en el símbolo de la cristianización de México (32-40). A Doña Isabel no se la culpa de la caída del imperio azteca. No así, a La Malinche quien ingresa en el Estado español como mujer indígena esclava no azteca. Como mujer indígena no azteca y esclava, su sexualidad, habilidad bilingüe y conocimientos son explotados por Cortés, pero sus actos son interpretados como traición dentro del discurso hegemónico de la nación que cristaliza en el México posrevolucionario. ${ }^{12}$ Aunque es verdad que en los anales indígenas la figura de la Malinche ocupa un lugar significativamente visible, también es verdad que no es la única, ya que también se observa el protagonismo de muchos otros actores a favor del bando español. Por esta razón, dadas las inestables circunstancias políticas que colocan a la Malinche en el centro de la atención política en su momento, tanto ella como otros actores indígenas es más que nada producto de esas circunstancias, ya que no hubo uno sino muchos actores políticos que en retrospectiva podrían ser vistos como traidores (Townsend 6-10). En el caso de la Malinche y de Doña Isabel Techichopotzin, si bien ambas mujeres parecen aliarse con el poder español, son explotadas sexualmente, puesto que conciben un hijo de Cortés, y por razones de clase y de servicio respectivamente reciben compensación, la Malinche es la única que parece llevar la culpa.

Conviene destacar la diferencia que "clase" y etnia parecen tener en la interpretación del protagonismo histórico de estas dos mujeres. Ninguna de ellas resiste, pero el hecho de que Doña Isabel Techichopotzin pertenezca a la elite azteca, a la clase en poder, parece eximirla de toda culpabilidad. La diferencia más profunda es que Doña Isabel Techichopotzin pertenece a la clase en poder mientras que la Malinche, como mujer esclava no azteca constituye el enigma de la otredad aun dentro del Estado indígena

12 Vea La Malinche in Mexican Literature (1991) de Sandra Messinger Cypess 41-90. Rebecca Earle discute la incorporación de signos indígenas, no necesariamente la Malinche, en el discurso nacionalista de la elite criolla en su texto The Return of the Native (2007) 1-20.

Revista Iberoamericana, Vol. LXXXII, Núm. 254, Enero-Marzo 2016, 103-121 
y seguirá siéndolo en el periodo colonial. Por lo tanto, el mito de la Malinche está inextricablemente ligado a engranajes de poder como género, clase y etnia. No obstante la diferente interpretación del protagonismo histórico de estas dos mujeres, arraigado en la diferencia de clase social y etnia, su suerte ilustra el grado de explotación al que las mujeres fueron, y aun hoy día son sometidas, puesto que son intercambiadas, otorgadas como sellos de alianzas, explotadss sexualmente contra su voluntad o voluntariamente por ninguna otra razón que por el simple hecho de ser mujeres. Éste es precisamente el nudo principal que Castellanos está tratando de penetrar y deshacer.

En su estudio sobre la representación de la Malinche, Sandra Messinger Cypess explica que a pesar de las grandes transformaciones en la sociedad española como resultado de la Conquista, la Conquista como tema no tuvo un lugar prominente en la producción literaria del Siglo de Oro español aunque sí formara parte de la historiografía (cartas, relaciones, historias oficiales, peticiones legales) del mismo (38). En contraste con el Siglo de Oro español, en México la Conquista aparece como tema de discusión, expresada en alegorías, en autos sacramentales como El divino Narciso de Sor Juana, o la versión náhuatl de El gran teatro del mundo de Calderón de la Barca escrita por Bartolomé de Alva, entre otros (Luciani 268-77), y aunque es parte de la producción literaria del barroco, la figura de la Malinche no llega a ocupar un papel protagónico. Temas asociados con la Conquista comienzan a aparecer en el periodo posterior a la independencia cuando había necesidad de restaurar y glorificar los vínculos con la cultura indígena anteriormente rechazados en la colonia (Messinger Cypess 26-40) y la necesidad de crear símbolos que representaran a la nueva nación (Earle 13-24). Sin embargo, aunque es en el periodo posterior a la independencia que el protagonismo histórico de la cultura indígena, en sus varios avatares, se debate en un sinnúmero de novelas, la aparición de la Malinche como personaje literario emerge después de la intervención francesa; y, en un proceso paulatino, que arranca a fines del siglo XIX, cristaliza en "malinchismo" en el discurso nacionalista del Estado mexicano posrevolucionario cuya ideología localizaba los valores sublimes de la nación en lo indígena (Messinger Cypess 41-80). De ahí que dentro de las narrativas hegemónicas de la nación, la Malinche sea en las palabras de Jean Franco una suerte de anti-Antígona (Conspiradoras 169-178). En efecto, su fama y su figura son incorporadas dentro del discurso hegemónico de la nación, acertadamente descrito en "Los hijos de la Malinche" de Octavio Paz como paradigma de traición. Paz describe la interpretación vigente de la Malinche en el discurso producido por el Estado posrevolucionario que la culpa, pasando por alto el protagonismo histórico de otros actores sociales cuyo proceder fue similar. De acuerdo con esta perspectiva la Malinche no cumplió con su papel de guardiana de los valores morales de la nación indígena que como mujer suponía representar y salvaguardar.

En el caso de Judith, la heroína de Castellanos parece estar consciente de su papel como mediadora del poder masculino, como soporte de un sistema que le exige

Revista Iberoamericana, Vol. LXXXII, Núm. 254, Enero-Marzo 2016, $103-121$ ISSN 0034-9631 (Impreso)

ISSN 2154-4794 (Electrónico) 
patriotismo sexual sin tomar en cuenta su voluntad o agencia y por ello se niega a hacerlo. En la "Judith" de Castellanos, Gabriel, el portador de la fusta, emite su orden: "Prepárate. Ha llegado tu hora" (356). Judith reacciona con extrañeza ya que ella no se considera diferente a las otras mujeres y acaba de quedar viuda: “¿Pero cómo han venido a señalarme? / Yo siempre estuve oculta a sus miradas" (356). Gabriel responde: "Los ancianos dan órdenes. No discuten razones [...]/ Cesa de resistir. Es Dios el que me ha enviado" (356-7). Judith implora ayuda a las mujeres a que busquen en sus corazones: "la piedad que los hombres expulsan de los suyos. / Miraos en mí [...]/ Mirad mi corazón, pequeño como el vuestro [...]/ Soy igual que vosotras. Sólo me aparta un signo / arbitrario y terrible como el de una leprosa" (357). Sin embargo, temerosas y obedientes, las mujeres hacen frente común, subrayan que el miedo las empuja a actuar como soporte de estructuras sociales que oprimen a otras mujeres: "Basta Judith. No tuerzas / el rayo hacia otras torres. / Un mandato de Dios es siempre justo" (358) dice una. Otra: "No resistas, Judith [...]/ deja que conduzcamos tu paso hacia el umbral / donde ya sólo Dios va a sostenerte" (359). Judith guarda silencio, reflexiona en voz alta acerca de su vida como mujer sumisa: "No, Judith no ha olvidado esa docilidad / de la mejilla al beso. / No, la voz de Judith no ha enronquecido / ni en las blasfemias ni en las amenazas, / no ha dejado escapar la tórtola que arrulla" (361). Luego sobrecogida por el desconcierto de haber sido elegida se arrodilla y "terriblemente lúcida" (361) pide ayuda a Dios, que no la escucha. Acto seguido, Judith, la humilde campesina de pies descalzos y vestido de percal, se levanta decidida y declara:

[...] no me moveré. Desde el gesto que esquivo

desencadenaré una destrucción

mayor que la que todos me han pedido [...]

De los que sobrevivan alguno ha de escupir mi nombre en una espesa saliva rencorosa.

Y yo caminaré entre maldiciones como entre un resplandor de violentas antorchas.

$[\ldots]$

Hasta que un día, todos, desemboquemos en el mar inmenso.

Se alzará la ciudad otra vez. Y otra vez la rodearán sus muros.

Y Judith, la soberbia que desdeñó la gracia, la que apartó la copa de elección de sus labios

Revista Iberoamericana, Vol. LXXXII, Núm. 254, Enero-Marzo 2016, $103-121$ ISSN 0034-9631 (Impreso)

ISSN 2154-4794 (Electrónico) 
se quedará, olvidada, como una tierra llena de sepulcros. (361-362)

Implícito en la negativa de Judith es el rechazo a las estructuras de un sistema social que depende en ella, pero en cuyo arbitrio de poder, a pesar de ser ella la piedra angular, no jugará un papel trascendental pues no tiene representación en éste último. De ahí que su negativa a obedecer el dictamen patriarcal traerá consigo el derrumbe del sistema. Lo que salta a la vista es la lucidez de su consciencia sobre las enormes consecuencias que su acto tendrá y el hecho de que sabe que entrará en el discurso oficial como culpable de la destrucción del sistema. La Judith de Castellanos es una heroína apocalíptica porque está consciente de que la destrucción que desencadenará será aún "mayor que la que todos me han pedido" (361); y lo hace con plena consciencia de que será maldecida por quienes sobrevivan la catástrofe y esta consciencia es de algún modo espeluznante y perturbadora.

\section{CONCLUSIÓN}

Cabe preguntar, ¿por qué crear una heroína apocalíptica que no actúa en defensa de su pueblo como la heroína bíblica? ¿Por qué hacer que su personaje asuma de manera consciente el hecho de que en la memoria de los sobrevivientes se la juzgará traidora? En vista de los paradigmas de comportamiento anteriormente discutidos que de algún modo encajonan a la mujer en una suerte de bocacalle, es posible arriesgar una respuesta: Judith se niega porque de hacerlo sería mero vehículo de realización del poder patriarcal encarnado en el drama por Gabriel, como representante del poder fálico. Reiteraría de este modo la función de la mujer como emblema de los valores morales de la nación y reforzaría el paradigma de comportamiento esperado de ella en el patriarcado. En el combate mortal entre estos dos enemigos (Dios-Nabucodonosor), ella no tiene otro papel sino el de mediadora del poder del más fuerte. En este sentido, Judith es el campo de batalla, el punto de encuentro donde estas dos voluntades chocan, se derrotan o ganan pero no una entidad en sí misma. Por esta razón, una vez ganada la batalla, una vez cumplida su misión sexual patriótica, Judith sería devuelta al espacio doméstico que supone salvaguardar y representar. En este sentido, perder o ganar no cambia en absoluto el entramado de poder en el que la mujer parece estar presa. La transformación completa de las relaciones de poder requiere del derrumbe completo del sistema que solo será posible con su negativa. Por consiguiente, su negativa y consecuente catástrofe abren un espacio para la creación de una sociedad más justa, una sociedad en la que la mujer sea partícipe de las decisiones que le atañen. En este sentido la Judith de Castellanos es una heroína destructora y creadora a la vez. Mas dado que su negativa a cumplir con el papel de femme fatale al servicio del sistema causa el derrumbe del sistema, será juzgada

Revista Iberoamericana, Vol. LXXXII, Núm. 254, Enero-Marzo 2016, $103-121$ ISSN 0034-9631 (Impreso)

ISSN 2154-4794 (Electrónico) 
como traidora dentro del guión cultural producido por el patriarcado. Sin embargo, es precisamente a través de la reescritura del mito de Judith que se ponen en tela juicio los paradigmas de comportamiento de la mujer como mera "esclava del Señor".

Más aún, ya que la historia de Judith en la que Castellanos basa su drama forma parte de un repertorio de paradigmas de comportamiento social que usan la excepcionalidad de la heroína como estrategia para encubrir la centralidad de la mujer en la realización del poder masculino, dejando intactas las estructuras que la limitan, su reescritura ha puesto en circulación un modelo de mujer diferente: un modelo de mujer que resiste porque es sujeto y posee agencia. En cierto modo, ya que paradigmas literarios operan como modelos de comportamiento social, en tanto que Castellanos pone en circulación un modelo de heroína que posee agencia, la reescritura del paradigma Judith es un acto de resistencia cultural en pro de la mujer. Como nos recuerda Teresa de Lauretis, la lucha de la mujer no solo debe ser llevada a cabo en el ámbito social, sino que tiene que fraguarse también en el ámbito discursivo puesto que es a través del discurso que se codifican y diseminan prácticas sociales que regulan la vida cotidiana. De ahí que textos y metáforas tengan consecuencias reales en la vida de hombres y mujeres (Lauretis 3). Es decir, en tanto que el significado de prácticas discursivas reside en paradigmas y metáforas y en tanto que éstas se reflejan en prácticas sociales, como es el caso de los paradigmas de mujer discutidos en este ensayo, el primer paso en la desconstrucción de dichos paradigmas sería su reescritura, la cual una vez puesta en circulación produciría un cambio en las prácticas sociales de las cuales forma parte integral.

La "Judith" (1952) de Castellanos pone en circulación una heroína que no es susceptible a ser domesticada como la heroína del Viejo Testamento sino que es una heroína que se resiste a seguir el rol establecido para ella en el guión cultural producido y controlado por el patriarcado de bases judeocristianas adaptado en México a las estructuras políticas de la nación. Judith es una heroína sombría precisamente porque ocasiona el derrumbe del sistema y porque va en contra de la ideología del Estado patriarcal dentro del cual la mujer es emblema de los valores más sublimes de la nación guardados en el hogar. Por eso, a pesar de las consecuencias nefastas de su negativa, este paso es necesario porque lo que está en juego no es únicamente la necesidad de volver visible lo invisible, sino de producir las condiciones de visibilidad para un sujeto de mujer diferente (Lauretis 9). En otras palabras, su acto de resistencia no está hecho en defensa de una entidad política (la nación) sino que va en pos de algo mayor: la transformación de las relaciones de género dentro de la polis, algo más difícil de alcanzar y sólo posible con la destrucción del sistema. Además, la "Judith" de Castellanos es aún más poderosa y amenazadora porque como mujer virgen interrumpe el circuito del poder controlado por el falo como único productor de significado simbólico. La "Judith" de Castellanos pone en circulación un nuevo modelo de heroína y, a través de la catástrofe, abre un espacio para la creación de una sociedad más justa en la que

Revista Iberoamericana, Vol. LXXXII, Núm. 254, Enero-Marzo 2016, $103-121$ ISSN 0034-9631 (Impreso)

ISSN 2154-4794 (Electrónico) 
la mujer produce significado y puede detentar poder político. Sin embargo, en el final del drama, dado que todavía no existía un contexto óptimo de aceptación de la mujer como sujeto, en cierta manera la mujer, aunque es una figura de resistencia, todavía se identifica con el espacio de la pérdida y por eso ocasiona la catástrofe a sabiendas de que se le acusará de ser traidora. No obstante, dado que su negativa causa la destrucción del sistema, la catástrofe ocasionada por ella abre un espacio para la creación de una sociedad más justa, una sociedad en la que la mujer participa plenamente en la vida política de la nación y puede y debe detentar poder dentro de ella. En este sentido la "Judith" de Rosario Castellanos es una heroína creadora de nuevos espacios, de nuevas cadenas de significación discursiva y de nuevas prácticas sociales.

\section{OBRAS CITADAS}

Ahern, Maureen. A Rosario Castellanos Reader: An Anthology of her Poetry, Sort Fiction, Essays, and Drama. Austin: U of Texas P, 1988.

Aínsa, Fernando. Identidad cultural de Iberoamérica en su narrativa. Madrid: Gredos, 1986.

Arenal, Electa y Yolanda Martínez-San Miguel. "Refocusing New Spain and Spanish Colonization: Malinche, Guadalupe, and Sor Juana". A Companion to the Literatures of Colonial America. Susan Castillo y otros. Malden: Blackwell, 2005. 174-194.

Bergero, Adriana y Elizabeth Marchant. "Feminists Insurrections." A Companion to Latin American Literature and Culture. Sara Castro-Klarén, ed. Malden: Blackwell, 2013. 509-530.

Brigley Thompson, Zoey Sorcha Gunne. "Breaking the Bonds ofDomination: Embodied Heroines, Rape Culture, and Possibilities of Resistance in Short Stories by Isabel Allende and Rosario Castellanos." Contemporary Women's Writing 7/3 (2013): 272-290.

Brine, Kevin R., Elena Ciletti y Henrike Lähnemann. The Sword of Judith: Judith Studies Across the Disciplines. Cambridge: OpenBook Publishers, 2000.

Butler, Judith. Antigone's Claim: Kinship between Life and Death. New York: Columbia UP, 2000.

Castellanos, Rosario. “Judith”. Obras completas. Vol. II. Poesía, teatro y ensayo. Eduardo Mejía, comp. México: FCE, 1998. 343-362.

Meditación en el umbral. Antología poética. Julián Palley, comp. México: Fondo de Cultura Económica, 1985.

Cruz, Sor Juana Inés de la. "Hombre necios...". The Answer / La respuesta. Electa Arenal y Amanda Powell, eds. y trads. New York: Feminist P-CUNY, 1994.

Earle, Rebecca. The Return of the Native: Indians and Myth-Making in Spanish America, 1810-1930. Durham: Duke UP, 2007.

Revista Iberoamericana, Vol. LXXXII, Núm. 254, Enero-Marzo 2016, 103-121 ISSN 0034-9631 (Impreso)

ISSN 2154-4794 (Electrónico) 
Engels, Frederick. The Origin of the Family, Private Property and the State. Chippendale, Australia: Resistance Books, 2004.

Franco, Jean. Spanish American Literature since Independence. New York: Barnes \& Noble, 1973.

Las conspiradoras. La represntación de la mujer en México. México: Fondo de Cultura Económica, 1994.

The Decline and Fall of the Lettered City: Latin America in the Cold War. Cambridge: Harvard UP, 2002.

Gámbaro, Griselda. "Antígona furiosa”. Teatro. Vol. 3Buenos Aires: Ediciones de la Flor, 1989. 195-217.

Glantz, Margo. La Malinche, sus padres y sus hijos. México, D.F.: Facultad de Filosofía y Letras-UNAM, 1994.

Hassig, Ross. Mexico and the Spanish Conquest. Oklahoma: U of Oklahoma P, 2006. Irigaray, Luce. This Sex Which is Not One. Catherine Porter y Carolyn Burke, trads. Ithaca: Cornell UP, 1985.

Jrade, Cathy. Modernismo, Modernity, and the Development of Spanish American Literature. Austin: U of Texas P, 1998.

Karttunen, Frances. Between Worlds: Interpreters, Guides, and Survivors. New Brunswick: Rutgers UP,1994.

Kolodny, Annette. "Dancing Through the Minefield." Feminisms: An Anthology of Literary Theory and Criticism. Robyn R. Warhol y Diane Price Herndl, eds. New Brunswick: Rutgers UP, 1997. 171-90.

Lauretis, Teresa de. Alice Doesn 't: Feminism, Semiotics, Cinema. Bloomington: Indiana UP, 1984.

León-Portilla, Miguel. Visión de los vencidos. Relaciones indígenas de la Conquista. México, D.F: UNAM, 1998.

Levine, Amy-Jill. "Sacrifice and Salvation: Otherness and Domestication in the Book of Judith." No One Spoke Ill of Her: Essays on Judith. James C. VanderKam, ed. Atlanta: Scholars P, 1992. 17-30.

Lévi-Strauss, Claude. Las estructuras elementales del parentesco. Barcelona: Paidós, 1981.

Lockhart, James y Bernardino de Sahagún. We People Here: Nahuatl Accounts of the Conquest of Mexico. Eugene: Wipf \& Stock, 1993.

Luciani, Frederick. "Spanish American theatre of the colonial period". The Cambridge History of Latin American Literature. Vol. 1. Roberto GonzálezEchevarría y Enrique Pupo Walker, eds. Cambridge: Cambridge UP, 1996. 260-285.

Messinger Cypess, Sandra. La Malinche in Mexican Literature from History to Myth. Austin: U of Texas P, 1991.

Migden Socolow, Susan. The Women of Colonial Latin America. Cambridge: Cambridge UP, 2000.

Revista Iberoamericana, Vol. LXXXII, Núm. 254, Enero-Marzo 2016, $103-121$ ISSN 0034-9631 (Impreso)

ISSN 2154-4794 (Electrónico) 
Miller, Beth Kurti. Women in Hispanic Literature: Icons and Fallen Idols. Berkeley: U of California P, 1983.

Morgades Besari, Trinidad. "Antígona”. Literatura de Guinea Ecuatorial (Antología). Donato Ndongo-Bidyogo y Mbaré Ngom, eds. Madrid: SIAL Ediciones, 2000. 427-433.

Nuccetelli, Susana y otros. A Companion to Latin American Philosophy. Malden: Wiley-Blackwell, 2010.

La nueva Biblia latinoamericana. Texto íntegro traducido del griego y del hebreo. Ramón Ricciardi y Bernardo Hurault, trad. Madrid: Ediciones Paulinas, 1972.

Paz, Octavio. El laberinto de la soledad. México: FCE, 1950.

Poniatowska, Elena. Hasta no verte, Jesús mío. México: Era, 1969.

Rama, Ángel. Transculturación narrativa en América Latina. México, D.F.: Siglo Veintiuno, 1982.

La ciudad letrada. Hanover, NH: Ediciones del Norte, 1984.

Salgado, María A.. "Mito, feminismo y femineidad en los poemas dramáticos de Rosario Castellanos". Explicación de Textos Literarios 24 (1995): 185-197.

Sánchez, Luis Rafael. La pasión según Antígona Pérez. Río Piedras: Editorial Cultural, 1993.

Stocker, Margarita. Judith Sexual Warrior: Women and Power in Western Culture. New Haven: Yale UP, 1998.

Swanson, Rosario M. de. “Utopía y distopía en 'Salomé', una pieza teatral poco conocida de Rosario Castellanos". Hispania 95/3 (2012): 437-447.Tarica, Estelle. "Rosario Castellanos at the Edge of Entanglement." The Inner Life of Mestizo Nationalism. Minneapolis: U of Minnessota P, 2008. 137-82.

Townsend, Camilla. Malintzin's Choices: An Indian Woman in the Conquest of Mexico. Albuquerque: U of New Mexico P, 2006.

Vidal, Hernán. Literatura hispanoamericana e ideología liberal, surgimiento y crisis. Una problemática sobre la dependencia en torno a la narrativa del Boom. Buenos Aires: Ediciones Hispamérica, 1976.

Zavala, Iris. Colonialism and Culture: Hispanic Modernisms and the Social Imaginary. Bloomington: Indiana UP, 1992. 
